\title{
AS ANÁLISES DE GÊNERO E A FORMAÇÃO DO CAMPO DE ESTUDOS SOBRE A(S) MASCULINIDADE(S)
}

\section{Márcio Ferreira de Souza ${ }^{1}$}

\begin{abstract}
Resumo
0 presente artigo aborda a construção do campo de estudos sobre a(s) masculinidade(s), entendendo-o como tributo da contribuição feminista. Faz-se um breve balanço dos estudos pioneiros, ressaltando particularmente 0 questionamento da masculinidade hegemônica (CONNELL, 1995) e, em seguida, discute-se sua penetração no Brasil a partir do debate sobre a crise do masculino e a noção de "novo homem", bem como a importância da perspectiva históricosocial para a compreensão das novas identidades masculinas.
\end{abstract}

Palavras-chave: Feminismo. Gênero. Identidades masculinas. Masculinidades.

\section{GENDER ANALYSIS AND THE MAKING OF FIELD OF MASCULINITY STUDIES}

\begin{abstract}
This article approaches the establishment of the study of masculinity(ies) by understanding it as a contribution of feminism. A short review of pioneering studies is carried out in order to highlight, in particular, the questioning of hegemonic

\footnotetext{
${ }^{1}$ Professor Adjunto do Departamento de Ciências Sociais da Faculdade de Artes, Filosofia e Ciências Sociais da Universidade Federal de Uberlândia (UFU). Doutor em Sociologia pela Universidade Federal de Minas Gerais. End. eletrônico: marciofsouza@fafcs.ufu.br
} 
masculinity (CONNELL, 1995) and, subsequently, the diffusion of masculinity studies in Brazil is discussed through the debate on the crises of the masculine and the notion of the "new man", as well as the importance of the historical-social perspective for the comprehension of the new masculine identities.

Keywords: Feminism. Gender. Masculine identities. Masculinities.

\section{INTRODUÇÃO}

artigo em tela visa refletir acerca da construção do campo de estudos sobre as masculinidades, entendendo-o como tributário das teorias de gênero. Este campo de estudos também deve se considerar em dívida com os movimentos feminista e LGBT, que estimularam pesquisadores à reflexão sobre a construção da masculinidade, refletindo-o sob perspectivas diversificadas, como a da desigualdade, a do poder e a do conflito. Para tanto, busco fazer um breve balanço dos estudos pioneiros, ressaltando a contribuição de Robert W. Connell (1995), autor que coloca em questão a noção de masculinidade hegemônica. Em seguida, aponto a inserção dos estudos sobre a masculinidade no Brasil, tendo como ponto de partida o debate sobre a crise do masculino e a conseqüente propagação da noção de "novo homem". Por fim, busco ressaltar a perspectiva histórico-social como importante para a compreensão das novas identidades masculinas

Cabe destacar que a tarefa de mapear a contribuição feminista para os estudos sobre homens e masculinidades foi trabalhada de forma competente em artigos assinados por autoras como Adriana Piscitelli (1998) e Karen Giffin (2005) e, também, em artigo mais recente como o de Benedito Medrado e Jorge Lyra (2008). Entretanto, meu interesse é o de centrar num rumo determinado que os debates acerca dos homens e masculinidades foram tomando, culminando numa ideia de "crise" da masculinidade e sua consequente concepção de "novo homem". Concepção esta que ganha espaço não só nos meios acadêmicos, mas nas mídias, de uma maneira geral.

\section{MASCUlinidAdes: ESTUdOS PIONEIROS}

Desde a década de 1960, os interesses pelos estudos sobre os homens e as masculinidades começaram a despontar nos países anglo-saxões, a partir da contribuição do movimento feminista e dos movimentos gay e lésbico, sobretudo 
ao colocar em questionamento a masculinidade hegemônica (KIMMEL, 1987)2. Robert W. Connell (1995) avança nessa discussão ao apontar para a multiplicidade das masculinidades, isto é, por diferenciados padrões que serão caracterizados como masculinidades hegemônicas, de subordinação, de cumplicidade e marginalizadas (CONNELL, 1995, p. 77-81). Connell fundamenta o conceito de hegemonia com base em Gramsci, cuja categoria é utilizada em sua análise das classes sociais. Porém, Connell atenta para o caráter volátil da hegemonia, já que os padrões de masculinidades variam localmente e historicamente. Entretanto, a masculinidade hegemônica tem como modelo de referência o patriarcado visto que no âmbito das relações de gênero vai se configurar como processo dominante dos homens e de subordinação das mulheres (CONNELL, 1995, p. 77).

Matos (2000b) desenvolve uma crítica a essa noção de hegemonia em Connell (1995) levantando o questionamento de que "do ponto de vista estrito da análise relacional de gênero, a "hegemonia" masculina nas civilizações ocidentais - em termos de dominação e/ou relações patriarcais e patrimoniais - é quase um pressuposto" (MATOS, 2000b; grifos da autora). Afirma, neste sentido, que é "delicado postular subordinação ou marginalização para as masculinidades", e chama atenção para o fato de que a masculinidade continua sendo dominante, pois, "nesta direção, ainda hoje é socialmente dominante um homem gay em relação a uma mulher lésbica, um homem negro em relação a uma mulher negra, um homem latino em relação a uma mulher latina e assim por diante" (MATOS, 2000b). 0 argumento de Matos é desenvolvido nos seguintes termos: "para a análise relacional dos gêneros (sempre no plural), ainda que o conceito gramsciano possa ser sofisticado e atender a necessidades teóricas específicas dentro do tema da masculinidade (...), ele vem impregnado da leitura marxista. Esta leitura tenta destacar com o conceito uma das características mais essenciais da filosofia da praxis marxista contemporânea que é a descrição deste processo a partir da dinâmica de uma sociedade baseada em classes" (MATOS, 2000b; grifos da autora). Por fim, a autora em questão destaca que

este fato ameniza e subtrai da dinâmica propriamente de gênero seu caráter autônomo, sua posição enquanto esfera definidora de padrões

\footnotetext{
${ }^{2}$ A noção de masculinidade hegemônica se processa a partir das relações de poder das quais resulta um modelo hegemônico calcado na representação paradigmática do homem heterossexual, branco e pertencente à classe dominante (KIMMEL, 1987). Este conceito encontrou grande recepção nos estudos de gênero que enfocam as masculinidades, como os de Connell (1995) e Hearn (1996). Acerca da questão sobre a multiplicidade de gêneros (masculino/feminino), consultar também Stoller (1993).
} 
interacionais relevantes à masculinidade pois a subentende à dinâmica das classes sociais. Além do mais a adoção da perspectiva marxista acaba se transformando num problema, justamente para o caráter RELACIONAL ENTRE OS GÊNEROS, pois esbarra em fronteiras politicamente complicadas já que, no mínimo, ameniza a assimetria relacional e radical de poder entre homens e mulheres, diluindo-a nas muitas e variadas posições políticas e culturais que ancoram lugares distintos para configurações de classes diferentes para as masculinidades (MATOS, 2006b; grifos meus).

Entretanto, concorda Matos que o conceito de hegemonia pode ser útil nos aspectos das relaç̧ões intragêneros (MATOS, 2000b).

Com relação ao aspecto da subordinação, Connell ressalta a existência de relações de subordinação intragênero, como no grupo de homens, onde os heterossexuais se adequam ao modelo dominante e os homossexuais fazem parte do modelo de subordinação. Mas este não é o exemplo único, já que homens heterossexuais também podem ser excluídos dependendo da posição social e econômica que ocupam. Desse modo, Connell aponta que o simbólico, na masculinidade subordinada, se aproxima ao simbólico da feminilidade (CONNELL, 1995, p. 79). Outro modelo de masculinidade destacado por Connell é o da cumplicidade. Este se efetua devido ao fato de que são poucos homens que, no plano da prática, cumprem o modelo normativo da masculinidade hegemônica. Mesmo que um grande número de homens tenha alguma conexão com este modelo, não chegam a adotá-lo porque ainda assim podem obter vantagens com a construção social da supremacia masculina - no que diz respeito à honra, prestígio e outros direitos - e ao mesmo tempo podem se distanciar dos conflitos possíveis aos quais estão propensos aqueles homens que se configuram nas práticas do modelo hegemônico (CONNELL, 1995, p. 79). Por fim, Connell ressalta a marginalização como sendo caracterizada pela relação entre masculinidades nas classes subordinadas ou grupos étnicos, atentando para o caráter sempre relativo da marginalização. Sua base argumentativa é a de que a relação entre marginalização e autorização pode existir também entre masculinidades subordinadas (CONNELL, 1995, p. 81) 3.

\footnotetext{
${ }^{3}$ Connell utiliza como exemplo o caso do escritor inglês Oscar Wilde que, ao se envolver numa relação homossexual com o Marquês de Queensberry, teve sua prisão decretada. Anteriormente Wilde já havia se relacionado com rapazes pertencentes à classe operária, mas estas relações não tiveram repercussão nas mesmas proporções do seu envolvimento com o aristocrata, pois se tratava de um grupo marginal e que não detinha a mesma relação de poder (CONNELL, 1995, p. 81).
} 
Os estudos pioneiros sobre a masculinidade apresentaram como grande contribuição uma tentativa de desconstrução crítica dos elementos constitutivos dos papéis masculino e feminino. Carrigan, Connell \& Lee (1985), por exemplo, propuseram as bases de uma nova sociologia da masculinidade ao criticar as formulações funcionalistas que se limitavam às teorias dos papéis. Entendo tal crítica como tributo da teoria feminista, visto que diversas autoras já haviam desenvolvido fortes críticas direcionadas à teoria dos papéis. Atentando, mais especificamente, para as teorias de gênero, sobretudo para os estudos que levam em conta as representações das atribuições sociais de gênero e suas transformações, podemos recorrer à noção de papéis sexuais, estabelecida por Parsons, quando este autor busca identificar a expectativa no comportamento de homens e mulheres na instituição familiar, instituição esta por ele considerada como um "sistema social". Conforme Parsons, instituição significa "uma pluralidade de papéis complementares e coordenados; por exemplo, a família, a escola, a fábrica" (apud ROCHER, 1976, p. 64). De acordo com esse enfoque, no seio da instituição familiar as expectativas sociais são construídas a partir dos valores da sociedade. Parsons identificou duas funções articuladoras e complementares no sistema familiar: a função instrumental-adaptativa atribuída aos homens, com o seu papel de pai e provedor e a função afetiva, exercida pela mãe. Tal identificação é, pois, dotada de uma visão reducionista acerca das expectativas sobre os papéis sexuais e encontra eco em um tipo de análise de caráter fundamentalmente essencialista. Críticas à teoria parsoniana são encontradas, entre outras autoras em Eagly (1987), Amâncio (1994), Aguiar (1996).

Connell (1995) buscou uma ruptura com os dominantes enfoques essencialistas preocupando-se em destacar que "a masculinidade não é objeto coerente acerca do qual se possa produzir uma ciência generalizadora" (CONNELL, 1995, p. 67), apontando a falta de clareza na própria definição do termo masculinidade. Seguindo esse princípio, cabe ressaltar a importância em discutir o sentido da masculinidade em seu aspecto plural. Judith Butler, por exemplo ao criticar um conceito unívoco de "mulher" que havia dominado o campo de estudo de gênero, reflete-o em seu sentido múltiplo. A tal visão cabe o argumento de que outras variáveis significativas (raça, classe social, etc.) estão direta e concretamente relacionadas à esfera de Gênero (BUTLER, 2003).

$\mathrm{Na}$ argumentação de Connell, todas as sociedades contam com registros culturais de gênero, mas nem todas possuem o conceito de masculinidade (1995, p. 67). 0 uso moderno deste termo assume que a própria conduta é resultado do 
tipo de pessoa que se é - uma pessoa não masculina se comportaria de modo diferente, seria pacífica, em vez de violenta, conciliatória em lugar de dominante, seria quase incapaz de dar um pontapé numa bola de futebol, indiferente na conquista sexual, etc. (1995, p. 67). Para o autor esta concepção pressupõe uma crença nas diferenças individuais e na ação pessoal, mas o conceito de masculinidade é inerentemente relacional. A masculinidade existe somente em contraste com a feminilidade (1995, p. 68). Na visão deste autor, a identificação do masculino em contraposição ao feminino se torna bastante problemática porque desponta o caráter essencialista que tem predominado no âmbito dos estudos sobre a masculinidade. Da mesma forma, os estudos sobre as mulheres também enfrentaram e continuam enfrentando tal problema. Connell desenvolve uma crítica ao modelo essencialista de interpretação, bem como estabelece críticas às definições positivistas, normativas e aos enfoques semióticos da masculinidade, apontando os limites que mais têm se destacado nos estudos sobre masculinidades (CONNELL, 1995).

Para Connell, as definições essencialistas usualmente recorrem a um viés que define o núcleo do masculino e lhe agregam uma série de vieses das vidas dos homens. Mesmo Freud se sentiu atraído por uma definição essencialista quando igualou a masculinidade com a atividade, em contraste com a passividade feminina - ainda que tenha considerado tal equação como demasiado simplificada. Este modelo tem como principal limite a arbitrariedade que carrega a eleição das essências do masculino e do feminino, visto que os partidários da perspectiva essencialista podem não estar de acordo entre si. Assim, as demandas acerca de uma base universal da masculinidade nos dizem mais sobre o ethos de quem efetua tal demanda, que sobre qualquer outra coisa (CONNELL, 1995, p. 68-69).

A concepção de masculinidade em Connell (1995) é estabelecida a partir da discussão do gênero como uma estrutura da prática social visto que, nos processos de gênero, a vida cotidiana está organizada em torno do cenário reprodutivo, definido pelas estruturas corporais e pelos processos de reprodução humana. Este cenário reprodutivo inclui o despertar sexual, o parto e o cuidado com a criança, as diferenças e similitudes sexuais corporais. 0 cenário reprodutivo é um processo histórico que envolve o corpo diferente da base biológica que está relacionada ao conjunto fixo de determinantes biológicos. Neste sentido, o gênero é uma prática social que constantemente se refere aos corpos e ao que os corpos fazem, mas não é uma prática social reduzida ao corpo. 0 gênero existe precisamente na medida em que a biologia não determina o social. 
A prática social é criadora e inventiva, mas isso não quer dizer que seja autônoma, já que responde a situações particulares e se gesta no seio das estruturas definidas de relações sociais. As relações de gênero, as relações entre pessoas e grupos organizados com o cenário reprodutivo, formam uma das principais estruturas da sociedade. 0 autor percebe a masculinidade e a feminilidade como projetos de gênero - estes são processos de configuração da prática através do tempo, que transformam seus pontos de partida nas estruturas de gênero.

Na década de 1970 foi demarcado o grande boom da produção teórica feminista. Giffin (2005) chama atenção para o fato de que houve uma recusa das feministas - em sua argumentação justificável, histórica e politicamente - da participação dos homens nas discussões feministas. Os estudos de gênero vão se consolidando, desde a década de 1960 com a produção de trabalhos desenvolvidos por mulheres pesquisadoras (GIFFIN, 2005; MEDRADO E LYRA, 2008). Giffin (2005) atenta para que os conceitos e discussões de gênero que foram apresentados por homens que presenciaram o (res)surgimento do movimento feminista nos países centrais na década de 1960, e que também foram atuantes em grupos de homens na década seguinte, foram significativos, visto que

A entrada destes homens nos estudos de gênero, sujeitos históricos situados em um contexto em que imperava uma visão crítica característica dos anos 60, e sem negar a dominação masculina, trouxe discussões importantes sobre os preços pagos e os problemas dos homens, antes pouquíssimo visíveis no Homem universalizado, reduzido ao "poder perante as mulheres" (GIFFIN, 2005, p. 55).

Giffin (2005) ressalta, em sua análise, que os homens que se propuseram a estudar as questões de gênero "adotaram uma visão dialética e histórica da realidade social dos gêneros, que relaciona o indivíduo com as ideologias e instituições sociais, sem determinismos mas também sem voluntarismos, num processo de constituição mútua, antítese da ótica binária da ciência objetivista" (GIFFIN, 2005, p.55).

A perspectiva da autora supracitada denota não apenas a importância da reflexão dos homens sobre as questões de gênero para o avançar de questões feministas - já consideravelmente avançadas aquela altura - como também ressalta a contribuição dos estudos de gênero para as reflexões dos estudiosos e estudiosas sobre os homens e as masculinidades.

Como aponta Piscitelli (1998), "no seio dos estudos de gênero" é que o interesse pela temática dos estudos de masculinidades vai se ampliando. Esta autora, porém, observa por uma ótica crítica, que "os autores que desenvolveram 
as melhores versões dos estudos de masculinidade marcam a distância entre esses trabalhos, inseridos nos estudos de gênero e os men's studies, considerados, esses sim, essencialistas e parciais" (PISCITELLI, 1998, p. 149). Tanto a análise de Pisticelli (1998) como a de Giffin (2005) destacam a relevância dos estudos sobre masculinidades desenvolvidos a partir de meados da década de 1980, sobretudo no que diz respeito à percepção da "diversidade de vozes masculinas" (Pisticelli, 1998, p. 149).

Medrado e Lyra (2008), por sua vez, ainda que também procurem destacar a relevância dos estudos sobre masculinidades, propriamente ditos, vão chamar atenção para o fato de que os trabalhos, em seus momentos iniciais, são "produzidos de maneira pouco sistemática, com concentração em autores específicos e sem necessariamente se desdobrarem em uma discussão teórica, epistemológica, política e ética ampla e consistente sobre o tema" (MEDRADO E LYRA, 2008, p. 809-810). Na década de 1990 já se torna possível falar em um "campo de pesquisas sobre masculinidades" (MEDRADO E LYRA, 2008) ${ }^{4}$.

A construção de um campo de estudos sobre a masculinidade foi apontada por alguns de seus autores pioneiros como tendo sido potencializado pela teoria feminista (CARRIGAN, CONNELL \& LEE, 1985; KIMMEL, 1987; ALMEIDA, 1995). Os estudos sobre as mulheres enfatizaram a dimensão do poder, seja através das análises de gênero (RUBIN, 1975; SCOTT, 1990; HARAWAY,1991) ou valendo-se do conceito de patriarcado (PATEMAN, 1993; MACHADO, 2000; SAFFIOTI, 2004). Os estudos sobre os homens também apontaram para a dimensão do poder, mas destacaram a existência de outras dimensões do poder (ALMEIDA, 1995; BOURDIEU, 2003).

\footnotetext{
${ }^{4}$ Cabe reproduzir uma citação de Medrado e Lyra (2008) acerca dessa ideia: "Buscando produzir uma organização dessas produções, especialmente aquelas publicadas entre 1995 e 2002, Robert (agora Rayween) Connell Jeff Hearn e Michael Kimmel publicam, em 2005, o Handbook of Studies on Men and Masculinities, no qual abordam o que eles denominam "desenvolvimento do campo de pesquisas sobre masculinidades", focalizando o modo como os estudos e pesquisas têm construído esse campo: desde um olhar "mais amplo e global" até a expressão "mais íntima e pessoal". Este, assim denominado, "campo" é, segundo esses autores, constituído a partir de produções que apresentam objetos distintos: 1. a organização social das masculinidades em suas "inscrições e reproduções" locais e globais; 2. a compreensão do modo como os homens entendem e expressam "identidades de gênero"; 3. as masculinidades como produtos de interações sociais dos homens com outros homens e com mulheres, ou seja, as masculinidades como expressões da dimensão relacional de gênero (que apontam expressões, desafios e desigualdades); 4. a dimensão institucional das masculinidades, ou seja, o modo como as masculinidades são construídas em (e por) relações e dispositivos institucionais" (MEDRADO E LYRA, 2008, p. 810).
} 
Bourdieu (2003) teorizou sobre a dominação masculina ao analisar a sociedade Cabila, um tipo de sociedade que explicita as diferenças sexuais como parte de um conjunto de oposições que reordena os atributos sexuais através de associações simbólicas vinculadas ao masculino e ao feminino. 0 autor utiliza o conceito de babitus através do qual defende a noção de que a reprodução da dominação masculina é possível porque há uma ordenação do mundo a partir de categorias particulares do pensamento masculino. Em suas palavras, aponta que "a força particular da sociodicéia masculina lhe vem do fato de ela acumular e condensar duas operações: ela legitima uma relação de dominação inscrevendo-a em uma natureza biológica que é, por sua vez, ela própria uma construção social naturalizada" (BOURDIEU, 2003, p. 33). 0 autor explicita que a dominação pode ser compreendida a partir da utilização de categorias construídas sob a perspectiva dos dominantes sobre as relações de dominação e, consequentemente, estas relações passam a ser vistas como "naturais" (BOURDIEU, 2003).

Matos (1997) desenvolve uma importante análise sobre a contribuição de Bourdieu para os estudos de gênero, ao mesmo tempo em que estabelece algumas críticas ao trabalho deste autor. Argumenta sobre a possibilidade de se buscar na obra de Bourdieu uma "leitura relacional de gênero", sobretudo quando este se refere ao mundo social como "espaço de luta”. Esta visão, segundo Matos, "desafianos a pensar na luta política entre dominados e dominantes a partir do recurso à divisão e binarismo de gênero, sobretudo a partir da possibilidade de identidades e culturas de gênero, fenômenos que são diariamente observáveis no nosso universo urbano e de modernidade tardia" (MATOS, 1987, p. 43). Por outro lado a referida autora aponta que, com relação às afirmaç̧ões de Bourdieu sobre a predisposição de que o masculino e o feminino possuem (em função dos esquemas das práticas e do habitus) de "ser suportes simbólicos privilegiados das significações e valores presentes numa visão falocêntrica de mundo" deve-se buscar romper tal visão "resgatando dimensões de gênero que priorizem características e aspectos distintos de uma ênfase sobre libido dominandi" (MATOS, 1987, p. 43).

No que diz respeito aos estudos pioneiros sobre a masculinidade, os conceitos de hegemonia e de dominação emergem como importantes categorias analíticas. Grande parte dos estudos sobre masculinidade, que foram desenvolvidos no Brasil, trabalharam com tais categorias, ao passo que buscaram também discutir diversas dimensões do poder. Por outro lado, são significativos os trabalhos que enfocaram 
as novas identidades masculinas e a multiplicidade das masculinidades que trouxeram à tona discussões sobre a emergência de um "novo homem".

\section{Os ESTUDOS SOBRE MASCULINIDADE NO BRASIL: A CRISE DO MASCULINO}

A contribuição de Connell foi considerável para o desenvolvimento dos estudos sobre masculinidade na América do Norte e Europa, assim como no Brasil. No caso brasileiro este autor contribuiu para uma série de abordagens que se concentraram mais na estrutura social do que nos indivíduos e seus papéis (Heilborn e Sorj, 1998). A partir dos anos 1990 o interesse pelos estudos sobre masculinidades vêm se desenvolvendo de maneira mais sistemática no país. Em 1985, porém, realizou-se aqui um "Simpósio do Homem", organizado por e para os homens (LISBOA, 1998, p. 131), que resultou em um livro intitulado MachoMasculino-Homem: a sexualidade, o machismo e a crise da identidade do homem brasileiro (COSTA, 1986). Uma das conclusões a que se chegou, a partir dos debates travados no referido Simpósio, foi a constatação de que os homens estavam vivenciando uma "crise". Crise esta fundamentada em diversas causas, dentre as quais foram destacadas as próprias transformações comportamentais das mulheres, na moral sexual, e nos questionamentos feministas contra a "posição dominadora e patriarcal dos homens na sociedade e na família" (LISBOA, 1998, p. 131).

Estabeleceu-se uma noção de "peso da masculinidade" sobre os homens, o que garantiu a preocupação inicial dos autores e autoras que atentaram para os estudos sobre as masculinidades no campo das ciências humanas, de modo geral. A visão sobre a crise do masculino já se fazia presente nos países centrais, a exemplo de trabalhos como o de Kimmel e Kaufman (1995) que destacaram tal crise como enraizada nas transformações globais e geopolíticas que se abalaram sobre os Estados Unidos, desde o início do século XX. Inicialmente se destacou uma concentração de estudos sobre os homens sob a perspectiva da sexualidade, ficando para o segundo plano importantes temáticas, tais como a da violência ou da paternidade, restritas a poucos estudos investigativos (LEAL e BOFF, 1996). Os estudos sobre os homens, felizmente, têm avançado em diversas perspectivas'.

\footnotetext{
${ }^{5}$ Os temas da violência e da paternidade, por exemplo, foram posteriormente trabalhados com mais intensidade. A título de exemplo temos: Cecchetto (2004) discutindo a violência urbana no Rio de Janeiro; e Arilha, Ridenti, Medrado (1998) que reuniram uma série de textos que abordam as dimensões do masculino sob a perspectiva da sexualidade e reprodução e sobre paternidade.
} 
Sandra Maria Garcia afirma, com razão, que estes estudos "têm seguido os mesmos passos teóricos e metodológicos dos estudos sobre mulheres, porém enfatizando a diversidade de modelos masculinos" (GARCIA, 1998, p. 31).

Muitos dos autores e autoras que refletiram inicialmente sobre as masculinidades no Brasil desenvolveram suas argumentações a partir de uma noção de crise dos homens como uma crise de um padrão de masculinidade hegemônica, o qual thes sobrecarregava com o peso da masculinidade. Esta preocupação, ainda que contestável, foi de grande importância para incentivar a reflexão sobre a construção social da masculinidade no Brasil. Luis Cuchinir (1992), Siloé Pereira Neves (1987), Roseli Buffon (1993), Maria Isabel Mendes de Almeida (1996), Sócrates Nolasco 1995a 1995b), Mirian Goldenberg (1991; 1992) e João Silvério Trevisan (1998) são algumas das referências que pensaram a crise do masculino no Brasil. Mas, os personagens que protagonizaram o cenário desta crise foram os homens das classes médias mais intelectualizadas, inseridos numa lógica individualista de cunho fortemente psicologizante (LISBOA, 1998, p. 132).

Conforme Lisboa (1998), boa parte dos autores se preocupou em explicar que a raiz do medo dos homens em redefinir sua identidade se encontra "no fato de que a masculinidade se constrói por oposição do que é culturalmente considerado feminino" (LISBOA, 1998: 133). Outros autores, porém, começam a refletir sobre as transformações a partir da idéia de que a masculinidade não implica necessariamente oposição à feminilidade. As discussões sobre um "novo homem" se inserem a partir daí, permitindo estabelecer uma relação com a temporalidade, vista que a visão acerca deste "novo homem" está relacionada a uma noção de transformação geracional - se vivemos em um novo tempo, um novo padrão de comportamento calcado em bases não tradicionais e mais flexíveis, se faz emergente.

A pauta da concepção de um "novo homem" (NOLASCO, 1995a) se coloca sem que ainda se tenha muita clareza de seu significado. A figura do "novo homem" - que já havia sido tomada como ponto de discussão em Connell (1985) como uma perspectiva alternativa ao rigoroso esquema dos papéis -, passa a ser discutida no Brasil por intelectuais como o psicanalista Sócrates Nolasco, fundador do Núcleo de Pesquisa sobre o Comportamento Masculino. Nolasco (1995a) abordou esta temática apontando que, embora a mídia passe a ressaltar a existência de um homem fragilizado e incapacitado de viver seus conflitos, alguns trabalhos apontam para a dificuldade que as mulheres encontram em entrar em contato com 
este homem fragilizado e em crise. As noções essencialistas se fazem presente visto que, ao se abordar dimensões da fragilidade, da crise e do conflito, muitos estudos desconsideram que estas são dimensões inerentes tanto ao masculino quanto ao feminino. Fragilidade, crise e conflito são compreendidos como dimensões essencialmente femininas. Resultante dessa percepção se sobressai uma noção de um novo modelo de homem: o que chora, que é fragilizado e assustado e necessita dividir o peso das grandes responsabilidades que lhes são cultural e socialmente impostas. Há uma projeção de um novo modelo enfocado na mudança do papel dos atores sociais masculinos.

0 trabalho de Nolasco se coloca como sendo de grande importância no sentido em que este autor se posiciona criticamente em relação às análises que se conduziram a partir das categorias do feminino e do masculino como se mantendo fiéis à "crença de uma essência masculina e feminina absoluta". Se a discussão acerca da noção de novo homem tiver estabelecida exclusivamente nessas bases, cria-se o ambiente favorável para o reforço de idéias, tão fortemente estruturadas, do homem como sujeito livre de conflitos e contradições. Ressalta Nolasco que "o novo homem é produto de mais uma possibilidade concedida pelo individualismo, e o que vem acontecendo não é ainda um movimento social" (1995 , p. 184).

Alguns termos sobre este novo homem aparecem na literatura que versa sobre as masculinidades, tal como a noção de "homem reconciliado" (BADINTER, $1992)^{6}$. 0 termo refere-se ao homem que concilia sua característica "dura" (masculina) com o seu lado "mole" (feminino). Eis a armadilha a que tais perspectivas estão propensas, pois, ao apontar características opostas ao significado do masculino e do feminino, reforçam estereótipos de uma essência totalizadora

\footnotetext{
${ }^{6}$ A idéia de reconciliação é uma perspectiva que leva em consideração noção de tempo, de etapas a ser superadas e de conflito a ser solucionados. 0 "homem reconciliado" é aquele idealizado - um homem futuro - que se torna homem sem anular o feminino. Badinter estabelece uma tipificação em três espécies de homem: o duro, o mole e o reconciliado. 0 homem "duro" é aquele que não cede e que se coloca à prova de que é homem a partir da valorização das características culturais cristalizadas socialmente que pressupõem o masculino, como a supervalorização da virilidade, por exemplo. Este tipo de homem é considerado uma espécie em extinção e faz parte do comportamento de uma geração nascida no final da década de 1950 e início da década de 1960. 0 homem "mole" é aquele que busca identificar o valor feminino e desprezar o culto à virilidade. 0 homem "reconciliado" é aquele que surge entre o homem "duro" e o homem "mole". Aquele dotado da capacidade de manter o seu aspecto masculino sem negar o feminino. É conciliador, flexível e mais apto à negociação no campo das relações afetivas.
} 
do que é ser homem e do que é ser mulher e, dessa forma, corre-se o risco de cair em uma contradição ao reforçar justamente aquilo que se critica (LISBOA, 1998).

Pistas que possibilitam compreender a noção de masculinidade são seguidas por Nolasco em seu texto Um "Homem de verdade" (1997). Ao retomar a percepção da crise masculina como ponto de partida para sua análise, Nolasco aponta a transcendência de uma abordagem individual já que esta crise se define como "parte de uma crise nos valores morais": é em um "vácuo moral" que a sociedade está assentada, através da exaltação dos valores materialistas, hedonistas, pela permissividade, por um relativismo desenfreado e os valores consumistas como forma de representação da liberdade contemporânea. Diante de tais valores a idéia de fracasso torna-se abominável e a noção de "homem de verdade" se assenta no processo pelo qual o menino é socializado. Ao se tornar adulto ele enfrentará a "ditadura do vencer" (NOLASCO, 1997, p. 15). É justamente a crise do masculino que se define perante esse processo de transição onde o homem ao se deparar com a obrigação de obter sucessivas vitórias se vê como sujeito que está fadado a enfrentar sucessivos fracassos (NOLASCO, 1997). Outra perspectiva apresentada por esse autor é a de que a transformação da intimidade torna-se uma das possibilidades abertas perante essa crise. A representação social do homem de verdade impõe aos homens uma série de dificuldades entre as quais se apresentam as restrições para estabelecer relações de intimidade. Isso ocorre porque ela não estimula nem concorre para a melhoria da comunicação emocional masculina, mas opostamente se alimenta do silêncio ou da comunicação monossilábica do indivíduo consigo mesmo (NOLASC0, 1997, p. 27).

A visão acerca das transformações na construção da identidade masculina - calcada no princípio da hegemonia - ganha grande espaço fora do âmbito acadêmico. São freqüentes os debates nas emissoras de rádio e televisão, além da propagação pela Internet, jornais e revistas de grande circulação nacional - como, por exemplo, Veja e Isto $E^{7}$. Os rumos que estes debates tomaram nesses veículos de massa estão mais vinculados a um discurso midiático que apregoa diferenciados estilos de vida voltados para o consumo, fazendo mais apologia de estilos de vida

\footnotetext{
${ }^{7}$ A edição de $1^{\circ}$. de outubro de 2003 da revista Veja trouxe uma matéria de capa intitulada "0 Novo Homem" na qual anuncia: "ele desenvolveu a sensibilidade, interessa-se mais pelos filhos, assume e exibe emoções, preocupa-se com a aparência, aprecia culinária e apurou o seu senso estético. É firme, mas tem estilo. Está nascendo o novo macho do século 21". A revista Isto É (20 de setembro de 2006), por sua vez, trouxe matéria assinada por Camilo Vannuchi e Lena Castellón, na qual identificam dois perfis masculinos: os que colocam poder e sucesso profissional acima de tudo e aqueles que elegem a família como prioridade absoluta.
} 
do que propriamente um debate político acerca da construção identitária dos homens e da reflexão sobre as interações de gênero. Alguns rótulos surgiram para identificar este "novo homem", como os já conhecidos metrossexual e übersexual, além do retrossexual ${ }^{8}$.

Natividade e Pimenta (2006) fazem uma análise da supracitada matéria de capa da Veja onde conduzem a discussão para três questões acerca da masculinidade: (a) há um movimento de reorganização da identidade masculina?; (b) a que "regime de verdade" (no sentido foucaultiano) a revista se refere e veicula quando faz apologia ao novo homem? e (c) quais são as relações de poder imbricadas no sistema discursivo desse texto? As autoras utilizam do recurso da análise multimodal para discutir as várias facetas de uma nova identidade masculina. Não cabe aqui entrar em detalhes acerca dos argumentos destas autoras, mas elas apresentam a conclusão de que a matéria traz a construção da masculinidade a partir de pressupostos hegemônicos, pois não se distancia das tradicionais imagens do guerreiro usando um jogo paradoxal de luz e sombra. As imagens são construídas e logo depois apagadas ou deixadas para que o leitor as construa (NATIVIDADE e PIMENTA, 2006, p. 121).

Para compreendermos melhor esse processo de uma suposta transformação identitária masculina, penso que uma perspectiva histórica assume grande importância para a compreensão dos processos de transformações da identidade de gênero masculina para a multiplicação das identidades nas quais é possível romper com o modelo hegemônico da masculinidade, conforme diversos autores e autoras vêm realizando?.

\footnotetext{
8 "Metrosexual" é um termo criado pelo escritor inglês Mark Simpson, para se referir ao homem vaidoso e sensível, aquele que "entende a alma feminina", acompanha as amigas às compras e é fundamentalmente urbano (daí o sentido de metrosexual). 0 termo "übersexual", identificado no livro "The Future of Men", de autoria dos publicitários Marian Salzman, Ira Matathia e Ann 0'Reilly, faz referência a um perfil de homem que é autoconfiante, possui um aspecto masculino e está determinado a alcançar os mais altos níveis de qualidade em todas as áreas de sua vida (SALZMAN, MALATHIA E 0'REILLY, 2005). 0 “retrossexual”, por exemplo, é o perfil do homem que se contrapõe ao metrossexual. Harvey Mansfield, professor de filosofia política da Harvard, é autor de "Manliness", livro onde critica a figura do metrossexual defendendo a tese conservadora do renascimento do homem-macho (MANSFIELD, 2006).

${ }_{9}$ Trato a questão da masculinidade sob uma perspectiva relacional, não-essencialista, apelando para a reflexão acerca das transformações sociais como chave para o entendimento da construção não de uma identidade de gênero masculina, mas sim considerando a multiplicidade das identidades de gênero (MATOS, 2000a).
} 


\section{A IMPORTÂNCIA DA PERSPECTIVA HISTÓRICO-SOCIAL PARA A COMPREENSÃO DAS NOVAS IDENTIDADES MASCULINAS}

Para uma melhor compreensão do processo desta passagem de uma identidade masculina posta, desta maneira, em seu termo singular (masculinidade hegemônica) para o seu sentido plural, como é possível identificar através de parte da literatura sociológica, faz-se importante ressaltar a questão sob uma perspectiva histórico-social. Neste sentido, o trabalho de Oliveira (2004) apresenta uma significativa contribuição visto que este autor, ao abordar a construção da masculinidade sob o ponto de vista da complexidade de elaborações culturais que possibilitam a emergência de um ideal de masculinidade, discute a questão partindo da análise das transformações que ocorreram na passagem do medievalismo para a modernidade. Este autor busca a perspectiva da modelação da masculinidade "a partir de uma sociogênese moderna que leva em conta algumas instituições decisivas para a emergência de suas características contemporâneas fundamentais" (OLIVEIRA, 2004, p. 15). Instituições tais como os Estados modernos, o miltarismo, a religião e o casamento com seu resultado direto: a família nuclear burguesa.

A modernidade se estabelece marcada pelos ideais de burguesia e masculinidade sob o jugo da religião onde podemos identificar que nos séculos XVIII e XIX. Tanto na Inglaterra quanto na Alemanha se consolidam a tradição puritana que pregava um ideal de masculinidade com a permanência do "controle sobre as paixões, a moderação e a pureza sexual e mental" (OLIVEIRA, 2004, p. 47). Temos a contínua presença da figura paterna no seio da vida familiar - figura ideal presente e enfatizada pelas diversas tendências cristãs que vai ao encontro dos ideais burgueses que emergem. Para Oliveira "a masculinidade penetrou-se na modernidade como símbolo de um ideal de permanência, que mantinha a vida social, a família e todas as tradições contra a loucura e o ritmo infernal das mudanças típicas da sociedade industrial" (OLIVEIRA, 2004, p. 48).

Em suma, analisando a construção social da masculinidade sob uma perspectiva histórico-social, Oliveira conclui que "o desenvolvimento e estabelecimento da família nuclear caminhou pari passu com a formação do Estado moderno". 0 desenvolvimento do Estado nacional significou a substituição do sentimento da linhagem medieval, favorecendo o ideal burguês de família e a família burguesa moderna, por sua vez, "tornou-se sinônimo de uma diferenciação 
exacerbada entre os sexos, de uma glorificação do laço mãe-filhos e de uma expectativa de que os homens sustentassem suas esposas e crianças" (OLIVEIRA, 2004, p. 50). Outra observação importante ressaltada pelo autor trata-se da idéia de infância e do pai provedor como fatores historicamente recentes visto que ainda nos dias atuais, o pai provedor nunca vingou de modo eficiente nos segmentos mais pobres, onde o orçamento familiar demanda o trabalho de outros membros da família, incluindo mães e filhos. Tal realidade não se difere muito dos primórdios da revolução Industrial, "quando mulheres e crianças eram exploradas de modo escorchante em extenuantes regimes de trabalho" (OLIVEIRA, 2004, p. 51). 0 ideal coletivo da família burguesa no século XIX contribuiu para a sacralização da figura do pai. Socialmente se construiu uma definição de papel centrado na figura do homem enquanto agente provedor, chefe de família responsável por atividades que demandam uma temporalidade voltada mais especificamente à dedicação ao trabalho remunerado, fora do âmbito doméstico.

A recente produção acadêmica que aborda a temática de gênero, enfocando especificamente a masculinidade, ganhou um grande impulso e uma ampliação para diversos focos discursivos. Os estudos sobre masculinidade, que antes eram mais restritos à sexualidade e reprodução, ganham terreno nos enfoques sobre 0 trabalho, a paternidade, a violência, dentre outros temas. Por outro lado, ganhouse à medida que os trabalhos sobre masculinidade passaram a ser discutidos sob o ponto de vista relacional. Neste sentido, autoras e autores como Piscitelli (1998), Matos (2000a, 2000b), Giffin (2005), Medrado e Lyra (2008), para citarmos alguns nomes que, no Brasil, trouxeram importantes contribuições para a análise do processo de construção do campo de estudos sobre as masculinidades, apontam para aspectos bastante significativos a este campo de estudos. Dentre tais aspectos se destacam, sobretudo, a reflexão sobre a masculinidade em seu sentido plural e os estudos de gênero levando em consideração sua dimensão relacional.

\section{Considerações Finais}

Um dos pontos básicos que procurei tratar neste texto diz respeito à idéia comum entre o/as estudioso/as do campo de estudos de gênero - em particular sobre as masculinidades - de que as sociedades contemporâneas passaram e estão passando por processos de transformações que afetaram significativamente as relações de gênero e familiares, introduzindo novos valores e novas identidades 
à representação da masculinidade ${ }^{10}$. Minha visão específica está relacionada à idéia de que a possibilidade de reflexão sobre a masculinidade e suas novas configurações, surge via contribuição (política e teórica) do movimento feminista. No caso brasileiro, o processo de transformação na representação da masculinidade foi refletido a partir da concepção de um "novo homem" que emerge neste cenário de transformações. As perspectivas sobre o "novo homem" estão assentadas justamente nas visões de que as transformações no âmbito das relações de gênero apontam para novas demandas nos padrões de comportamento social e na aquisição de valores que rompem com padrões rígidos de comportamento e de representações do masculino e do feminino $0^{11}$. Desse modo, cabe afirmar que as contribuições feministas foram primordiais para o desenvolvimento do campo de estudos sobre as masculinidades, ao apresentar um amplo sistema de idéias que propuseram um alcance mais geral acerca da vida social, deixando um legado no que diz respeito à compreensão do mundo do ponto de vista das mulheres. Neste sentido, a teoria feminista se construiu rompendo com a invisibilidade à qual as mulheres estavam acometidas no campo da investigação social e tem um significado tão importante quanto a perspectiva marxista que demonstrou que 0 mundo pode ser visto do ponto de vista dos trabalhadores.

Lengermann \& Niebrugge-Brantley, por exemplo, apontam a teoria feminista, ao romper a invisibilidade das mulheres, encontra um paralelismo em Marx, visto que foi este autor que contribuiu para o conhecimento que temos da sociedade, que se supõe constitui uma expressão absoluta e universal da realidade, reflete, de fato, a experiência dos que dirigem política e economicamente o mundo social. Marx demonstrou que o mundo pode ser observado do ponto de vista dos trabalhadores que, embora sejam subordinados política e economicamente, são os produtores indispensáveis do nosso mundo. As autoras supracitadas salientam que as questões teóricas do feminismo nos levam a descobrir que o que havíamos

\footnotetext{
${ }_{10}$ Tais processos de transformações foram identificados por diversos autores e autoras que apresentaram variações sobre o mesmo tema. Denominações diferenciadas para visões comuns foram apresentadas: sociedades materialistas e pós-materialistas (INGLEHART, 1997), sociedades industriais e pós-industriais (BELL, 1978), modernidade (GIDDENS, 1991), sociedades pósmodernas, tradicionalismo e "destradicionalismo" (HEELAS, LASH e MORRIS, 1996). Uma indicação de leitura acerca desta discussão encontra-se em Matos (2005).

${ }^{11} 0$ que não significa que a concepção de "novo homem" seja bastante questionável. Desenvolvo com mais detalhes esta discussão em minha tese de doutorado (SOUZA, 2007), sob orientação de Neuma Aguiar. Conferir também artigo de minha autoria: "Transição de valores e a perspectiva sobre o novo homem”. Ver Souza (2010, no prelo).
} 
considerado que constitua conhecimento universal e absoluto do mundo é, na realidade, um conhecimento derivado das experiências de um segmento poderoso da sociedade, os homens como "amos". Ao redescobrir o mundo este conhecimento se relativiza (LENGERMANN \& NIEBRUGGE-BRANTLEY, 2002, p. 382).

Por outro lado, com relação às teorias da masculinidade, podemos destacar que diversos autores e autoras que se debruçaram sobre a investigação acerca dos homens, de um modo geral, apontaram a tese inicial deste campo de estudo como "produto" da teoria feminista.

\section{REFERÊNCIAS}

AGUIAR, Neuma. "Grupo Doméstico, Gênero e Idade: análise longitudinal de uma plantação canavieira". Tese de Concurso para professora titular apresentada ao Departamento de Sociologia e Antropologia, Faculdade de Filosofia e Ciências Humanas da Universidade Federal de Minas Gerais, Belo Horizonte, 1996.

ALMEIDA, Maria Isabel Gomes de. Masculino/Feminino: tensão insolúvel. Rio de Janeiro: Rocco, 1996.

ALMEIDA, Miguel Vale de. Senhores de si. Lisboa: Fim de século, 1995.

AMÂNCIO, Lígia. Masculino e feminino. A construção social da diferença. Porto: Edições Afrontamento, 1994.

ARILHA, Margareth; RIDENTI, Sandra; MEDRADO, Benedito (orgs.). Homens e masculinidades: outras palavras. São Paulo: ECOS/Ed. 34, 1998.

BADINTER, Elisabeth. XY: sobre a identidade masculina. Rio de Janeiro: Nova Fronteira, 1992.

BELL, Daniel. 0 advento da sociedade pós-industrial: uma tentativa de previsão social. São Paulo: Editora Cultrix, 1978.

BOURDIEU, Pierre. A dominação masculina. Rio de Janeiro: Bertrand do Brasil, 2003.

BUFFON, Roseli. Reconstruções da imagem masculina em um grupo de homens das camadas médias intelectualizadas. IV Reunião Regional/ABA/Sul, Sessão: Construção da Identidade Masculina. Florianópolis, nov. 1993. 
BUTLER, Judith. Problemas de gênero: feminismo e subversão da identidade. Rio de Janeiro: Civilização Brasileira, 2003.

CALDAS, Dario (org.). Homens: comportamento, sexualidade, mudança. São Paulo: Editora Senac, 1997.

CARRIGAN, Tim; CONNELL, Robert William \& LEE, John. Hard and heavy: Toward a new sociology of masculinity. In: KAUFMAN, Michael (ed.). Beyond patriarchy: essays by men on pleasure, power, and change. Oxford University Press, TorontoNova York, 1985, p. 139-182.

CECCHETTO, Fátima Regina. Violência e estilos de masculinidade. Rio de Janeiro: Editora FGV, 2004.

CONNELL, Robert W. Masculinities: knowledge, power and social change. Berkeley: University of California Press, 1995.

CONNELL, Robert. W., HEARN, Jeff, and KIMMEL, Michael. Introduction. In: KIMMEL, Michael, HEARN, Jeff, and CONNELL, Robert. W. (eds.). Handbook of Studies on Men and Masculinities. California: Sage Publications, 2005. p. 1-12. COSTA, Moacir (Org.). Macho-Masculino-Homem. São Paulo: L\&PM, 1986.

CUCHINIR, Luiz. Feminino-Masculino. Rio de Janeiro: Rosa dos Tempos, 1992. EAGLY, Alice. Sex Differences in Social Behavior: A social-role interpretation. New York: Earlbaum, 1987.

GARCIA, Sandra Mara. Conhecer os homens a partir do gênero e para além do gênero. In: ARILHA, Margareth; RIDENTI, Sandra; MEDRADO, Benedito (orgs.) Homens e masculinidades: outras palavras. São Paulo: ECOS/Ed. 34, 1998, p. $31-50$.

GIDDENS, Anthony. As conseqüências da modernidade. São Paulo: Unesp, 1991. . A transformação da intimidade: sexualidade, amor e erotismo nas sociedades modernas. São Paulo: Unesp, 1992.

GIFFIN, Karen. A inserção dos homens nos estudos de gênero: contribuições de um sujeito histórico. Ciência e Saúde Coletiva, Rio de Janeiro, v. 10, n. 1, 2005, p. 47-57.

GOLDENBERG, Mirian. Ser homem, ser mulher: dentro e fora do casamento. Rio de Janeiro: Revan, 1991.

HARAWAY, Donna. Simians, cyborgs, and women: the reinvention of nature. New York: Routledge, 1991. 
HEARN, Jeff. Is masculine dead? A critique of the concept of masculinity/ masculinise. In: GHAIL, Máirtín Mac an. Understanding Masculinities: social relations and cultural arenas. Buckingham, Philadelphia: Open University Press, 1996, p. 202-217.

HEILBORN, Maria Luiza; SORJ, Bila. Estudos de gênero no Brasil. In: MICELI, Sérgio. (org.). O que ler na ciência social brasileira (1970-1995). São Paulo: Sumaré/ANPOCS, v. 2, 1998. pp. 183-221.

HEELAS, Paul; LASH, Scott; MORRIS, Paul. Detraditionalizaton. Cambridge: USA \& Oxford, UK: Blackwell, 1996.

INGLEHART, Ronald. Modernization and postmodernization: cultural, economic and political change in 43 societies. Princeton University Press. 1997.

KIMMEL, Michael S. The cult of masculinity: American social character and the legacy of the cowboy. In: KAUFMAN, Michael (ed.). Beyond patriarchy: essays by men on pleasure, power, and change. Toronto-New York: Oxford Universty Press, 1987, p. 235-249.

KIMMELL, Michael \& KAUFMAN, Michael. Weekend warriors: the new men's movement. Profeminist men respond to the mythopoetic men's movement (and the mythopoetic leaders answer). In: KIMMELL, Michael \& KAUFMAN, Michael (org.). Politics of Manhood. Philadelphia: Temple University Press, 1995, p. 1639.

LEAL, Ondina Fachel; BOFF, Adriane de Mello. Insultos, queixas, sedução e sexualidade: fragmentos de identidade masculina em uma perspectiva relacional. In: PARKER, Richard; BARBOSA, Regina M. (orgs.). Sexualidades Brasileiras. Rio de Janeiro: Relume-Dumará/Abia/IMS/UERJ, 1996, p. 119-135.

LENGERMANN, Patricia Madoo \& NIEBRUGGE-BRANTLEY, Jill. Teoria feminista contemporánea. In: Ritzer, George. Teoria sociológica moderna. Madrid: McGraw-Hill/Interamericana de Espana, 2002, p. 379-442.

LISB0A, Maria Regina Azevedo. Masculinidade: as críticas ao modelo dominante e seus impasses. In: PEDRO, Joana Maria; GROSSI, Miriam Pillar. Masculino, feminino, plural: gênero na interdisciplinaridade. Florianópolis: Ed. Mulheres, 1998, p. 131-138.

MACHADO, Lia Zanotta. Perspectivas em confronto: relações de gênero ou patriarcado contemporâneo? UnB, Departamento de Antropologia - DAN, 2000. Disponível em: < http://www.unb.br/ics/dan/Serie284empdf> . Acesso em 14/02/07. 
MANSFIELD, Harvey C. Manliness. New Haven: Yale University Press, 2006.

MATOS, Marlise. Pierre Bourdieu e o gênero: possibilidades e críticas. In: Série estudos, 94. Rio de Janeiro: IUPERJ, setembro, 1997, p. 3-49.

Reinvenções do vínculo amoroso: cultura e identidade de gênero na modernidade tardia. Belo Horizonte: Ed. UFMG; Rio de Janeiro: IUPERJ, 2000a.

. Dimensões da Masculinidade no Brasil. In: I Simpósio Internacional 0 Desafio da Diferença: articulando gênero, raça e classe. Salvador: 09 a 12 de abril de 2000. Disponível em <http://www.desafio.ufba.br/gt7-004.html>. Acesso em 18/06/07.

. A democracia não deveria passar na porta de casa: a criação de índices de tradicionalismo e de destradicionalização de gênero no Brasil. In: ARAÚJ0, Clara; SCALON, Celi (orgs.) Gênero, familia e trabalho no Brasil. Rio de Janeiro: FGV, 2005, p. 89-122.

MEDRADO, Benedito e LYRA, Jorge. Produzindo sentidos sobre o masculino: da hegemonia à ética da diversidade. In: ADELMAN, Mirian; SILVESTRIN, Celsi (Orgs.). Coletânea Gênero Plural. Curitiba: UFPR, 2002. p. 63-76.

Por uma matriz feminista de gênero para os estudos sobre homens e masculinidades. Estudos Feministas, Florianópolis, 16(3), setembrodezembro/2008.

NATIVIDADE, Claudia e PIMENTA, Sonia. A construção semiótica da masculinidade na modernidade. Teoria e Sociedade, Belo Horizonte, n. 14.1, jan-jun, 2006, p. 100-125.

NEVES, Siloé Pereira. Homem, mulher e medo: metáforas da relação homemmulher. Rio de Janeiro: Vozes, 1987.

NOLASCO, Sócrates. Um "Homem de Verdade". In: CALDAS, Dario (org.). Homens. São Paulo: Editora SENAC, 1997, p. 13-29. . O mito da masculinidade. Rio de Janeiro: Rocco, 1995a. . (org.). A desconstrução do masculino. Rio de Janeiro: Rocco, 1995b.

OLIVEIRA, Pedro Paulo. A construção social da masculinidade. Belo Horizonte: Editora UFMG; Rio de Janeiro: IUPERJ, 2004.

PATEMAN, Carole. O contrato sexual. São Paulo: Paz e Terra, 1993.

PISCITELLI, Adriana. Gênero em perspectiva. Cadernos Pagu, Campinas, n. 11, 1998, p. 141-157. 
RITZER, George. Teoria sociológica moderna. Madrid: McGraw-Hill/ Interamericana de Espanha, S.A.U, 2002.

ROCHER, Guy. Talcott Parsons e a sociologia americana. Rio de janeiro: Francisco Alves, 1976.

RUBIN, Gayle. The traffic in Women. Notes on the "political economy" of sex. In: REITER, Rayna. (ed.). Toward an antropology of women. New York, Monthly Review Press, 1975.

SAFFIOTI, Heleieth. Gênero, patriarcado, violência. São Paulo: Fundação Perseu Abramo, 2004.

SALZMAN, Marian.; MATHATIA, Ira and 0'REILLY, Ann. The future of men: the rise of the ubersexual and what he means for marketing today. Palgrave MacMillan, 2006.

SCOTT, Joan. Gênero: uma categoria útil para análise histórica. Educação e Realidade, Porto Alegre, vol. 16, julho-dezembro, 1990, p. 5-22.

SCOTT, Joan. Prefácio à Gender and Politics of History. Cadernos Pagu, Campinas, n. 3, 1994, p.11-28.

SOUZA, Márcio Ferreira de. A percepção do tempo na vida cotidiana sob a perspectiva de gênero: o dia-a-dia em Belo Horizonte. Tese de doutorado, Sociologia, Faculdade de Filosofia e Ciências Humanas, Universidade Federal de Minas Gerais, Belo Horizonte, 2007.

. Transição de valores e a perspectiva sobre o novo homem. In: SOUZA, Márcio Ferreira de (org.). Desigualdades de gênero no Brasil: novas ideias e práticas antigas. Belo Horizonte: Argvmentvm, 2010 (no prelo).

STOLLER, Robert. Masculinidades e feminilidades: apresentações de gênero. Porto Alegre: Artes Médicas, 1993.

TREVISAN, João Silvério. Seis balas num buraco só: a crise do masculino. São Paulo: Record, 1988.

VEJA. 0 homem em nova pele. Edição de $1^{\circ}$. de outubro de 2003.

VANNUCHI, Camilo e CASTELLÓN, Lena. Quem é o novo homem. ISTO É. Edição de 20 de setembro de 2006. 